\title{
Alloxan diabetes alters the tensile strength, morphological and morphometric parameters of abdominal wall healing in rats ${ }^{1}$
}

\author{
José Guilherme Minossi ${ }^{\mathrm{I}}$, Flávio de Oliveira Lima ${ }^{\mathrm{II}}$, Carlos Antonio Caramori ${ }^{\mathrm{II}}$, Claudia Nishida Hasimoto ${ }^{\mathrm{IV}}$, Érica Veruska \\ Paiva Ortolan", Paulo Antônio Rodrigues ${ }^{\text {VI }}$, César Tadeu Spadella ${ }^{\text {II }}$ \\ IPhD, Assistant Professor, Departament of Surgery and Orthopedics, Faculty of Medicine, Sao Paulo State University (UNESP), Botucatu-SP, Brazil. \\ Conception, design, intellectual and scientific content of the study; acquisition and interpretation of data; technical procedures; manuscript writing. \\ IIPhD, Assistant Professor, Department of Pathology, Faculty of Medicine, UNESP, Botucatu-SP, Brazil. Histophatological analysis. \\ ${ }^{I I I} \mathrm{PhD}$, Associate Professor, Department of Medical Clinic, Faculty of Medicine, UNESP, Botucatu-SP, Brazil. Morphometric analysis.

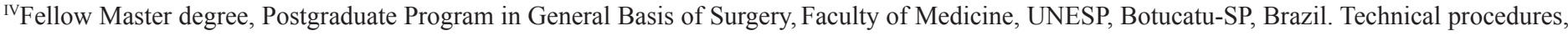 \\ interpretation of data. \\ ${ }^{v} \mathrm{PhD}$, Assistant Professor, Department of Surgery and Orthopedics, Faculty of Medicine, UNESP, Botucatu-SP, Brazil. Acquisition and interpretation \\ of data. \\ ${ }^{\mathrm{V}} \mathrm{PhD}$, Assistant Professor, Departament of Surgery and Orthopedics, Faculty of Medicine, UNESP, Botucatu-SP, Brazil. Acquisition of data, manuscript \\ writing. \\ VIIPhD, Full Professor, Department of Surgery and Orthopedics, Faculty of Medicine, UNESP, Botucatu-SP, Brazil. Critical revision.
}

\begin{abstract}
PURPOSE: To investigate the effects of alloxan diabetes on the abdominal wall healing of rats undergoing laparotomy.

METHODS: Ninety-six male Wistar rats weighing between 200 and 300 grams, divided into two groups: non-diabetic group (G1) and another with untreated diabetes (G2). Three months after diabetes induction, the animals underwent a 5cm-long- laparotomy and 5.0 nylon monofilament suture. After the surgery, 12 animals from each group were euthanized on days 4, 14, 21 and 30 corresponding to the moments M1, M2, M3 and M4. In each moment a fragment of the abdominal wall containing the scar was removed for tensile strength measurement, histological and morphometric study. Clinical and biochemical parameters were also analyzed.

RESULTS: G2 animals showed parameters compatible with severe diabetes and decreased plasma levels of insulin. The tensile strength in G2 was significantly smaller in M2 and M4, with a tendency to fall in the other two. Through light microscope, diabetic animals showed more difficulty to increase collagen density and contraction. G2 animals showed high cellularity of fibroblasts in later healing moments, with collagen thinning in M2 and M4.
\end{abstract}

CONCLUSION: The abdominal wound healing in untreated diabetic animals was altered and led to a higher incidence of dehiscence and infections.

Key words: Diabetes Mellitus. Alloxan. Tensile Strength. Wound Healing. Histology. Rats. 


\section{Introduction}

Diabetes mellitus (DM) is now a public health problem worldwide. Data from the American Diabetes Association, 2011, estimated that there are 25.8 million diabetics in the U.S., with the occurrence of 1.9 million new cases in 2010, with a total annual cost to the health system in that country of 174 billion dollars in $2007^{1}$. Projections from epidemiological data about diabetes from 191 countries, members of the World Health Organization, estimated the existence of 366 million diabetics in the world by the year 2030 , equivalent to $4.4 \%$ of the world population ${ }^{2}$.

In Brazil, the situation is not much different. With bases in a matrix calculation organized by the Diabetes Brazilian Society $^{3}$, and taking as reference the latest census conducted by the IBGE, in 2010, it is possible to estimate that $6.7 \%$ of the Brazilian population is diabetic, the equivalent to 12.7 million people, of whom $10 \%$ are carriers of type 1 diabetes and an estimated $50 \%$ are unaware of their ill condition, possibly being identified in the future, through a chronic complication of the disease.

According to the latest Brazilian Consensus on Diabetes ${ }^{4}$, diabetes is the sixth most frequent cause of hospitalization, as the underlying cause of ischemic heart disease, heart failure, stroke and hypertension. It accounts for $30 \%$ of admissions with chest pain in the coronary care units, and is the leading cause of lower limb amputation and acquired blindness; furthermore, $26 \%$ of patients who start dialysis are diabetic.

Despite the myth ingrained in medical and popular culture that "diabetics poorly heal their wounds," there are few studies that clearly demonstrate the real effects of the disease on the biological process of wound repair. It is known, however, that half of diabetic patients require a surgical procedure during their lives, and approximately $25 \%$ of them will have their disease identified in this moment ${ }^{5}$.

It is known that diabetes delays the closure and contraction of the surgical wound, acts negatively on granulocytes, on chemotaxis of leukocytes and macrophages, affects collagen metabolism, red blood cells and the biomechanical characteristics of the surgical wound ${ }^{5,6}$.

Although studies on the healing abnormalities in diabetes are well known in various organs and tissues, such as bone, small intestine, colon, heart, blood vessels and nerves, little is known about the effects of this disease on the healing of the abdominal wall.

This study aimed to analyse the effects of diabetes mellitus on the abdominal wall of rats by analyzing the tensile strength, morphometry and histology.

\section{Methods}

The study was developed after approval of the Experimental Research Ethics Committee of UNESP (Protocol $\mathrm{n}^{\mathrm{o}}$ 651) and follows the Council for International Organization of Medical Sciences (CIOMS) ethical code for animal experimentation.

Ninety-six clinically healthy male Wistar rats, weighing between 200 and 300 grams, and with approximately three months of age were used. They were provided by the Central Vivarium of the Campus of Botucatu - UNESP.

The animals were housed in polyurethane boxes in groups of four animals per cage, with food and water provided ad libitum. After an adaptation period of seven days, they were prophylactically treated against worms with mebendazole $(25 \mathrm{mg} /$ $\mathrm{kg}$ body weight / day), for three days.

After the adaptation period, the animals were randomized into two groups, a control non-diabetic group (G1) and a diabetic one, without any treatment of the disease $(\mathrm{G} 2)$. The G2 animals received an intravenous injection of alloxan $2 \%$ at a dose of 42 $\mathrm{mg} / \mathrm{kg}$ body weight. After induction of diabetes, the animals were monitored for 14 days, aiming at the selection of severe diabetic animals. Those animals who had fasting glucose above $200 \mathrm{mg} / \mathrm{dl}$ and urinary glucose greater than $3+$ in two successive doses (seven and 14 days after induction) were considered severe diabetic animals, accompanied by significant increases in water intake and urine output. Animals that did not meet the clinical and laboratory criteria mentioned above were excluded from the study.

Three months after diabetes induction, all animals (G1 and G2) underwent a 5cm-long- laparotomy. The synthesis of abdominal wall was performed with separate stitches, $2 \mathrm{~mm}$ apart from each other, with 5.0 nylon monofilament suture. In each group, a new draw was held for the definition of the moments of investigation.

After the surgery, 12 animals in each group were euthanized on days 4, 14, 21 and 30, corresponding respectively to the moments M1, M2, M3 and M4 of healing. Out of the 12 animals euthanized at each time, six were randomly selected for histopathological study with optical and morphometric analysis of the area occupied by collagen fibers in the scar. A rectangular segment of the abdominal wall was removed in all animals, $5 \mathrm{~cm}$ length and $2 \mathrm{~cm}$ in width, for measuring the breaking strength of the scar.

From the fragments obtained from the abdominal wall, the skin containing the scar was carefully dissected and removed. In the sequence, the wall was perpendicularly sectioned to the suture 
line obtaining three segments of $1 \mathrm{~cm}$ in width. One fragment was used for histopathology, another for breaking strength and the rest was discarded.

For the study of breaking strength, the segment was placed in a container with saline at $37^{\circ} \mathrm{C}$ its value was and immediately quantified. For this biomechanical study, the Universal Testing Machine Mechanics - EMIC, model DC 10000 was used.

To perform the morphometric analysis, the segment was fixed in formaldehyde solution $10 \%$ for 48 hours and then immersed in $70 \%$ alcohol for 24 hours, embedded in paraffin, cut into sections of $0.5 \mathrm{~mm}$ in thickness and stained with hematoxylin and eosin (HE) and Masson trichrome. The two colorings were performed in all fragments obtained, and the analysis of the slides was performed objectively by the same pathologist without prior knowledge of the group to whom the animal belonged.

The slides stained with Masson were used for quantification of collagen fraction present in the scar areas through a video-densitometry system. Areas of $2 \mathrm{~cm} \times 0.5 \mathrm{~cm}$ (AOI - Area of Interest) in the region of the scarring between the margins defined by the muscles on both sides of the scar were analyzed, using an optical microscope (Leica DMLB, x10 ocular Lplan / 25, PL Fluotar 5x objective), whose image was captured by camera (Köhler CTV 500, NTSC coupler lens $\mathrm{x} 0.63$ ) and digitized by computer (AST Bravo MS-T 6200 PRO, Pentium Pro, Windows NT system) using Image Pro-PlusTM Software, Version 3.0 (Media Cybernetics, Silver Spring, Maryland, USA, 1997).

The tissue elements were identified according to the color levels of the area of interest (AOI). The digitized profile was analyzed by computer that calculated the volume fraction occupied by fibrosis as the sum of the whole area of fibrous tissue, divided by the total area of the segment. The fibrosis fraction corresponds to a relative measure $(\%)$ of fibrosis content over the entire wall cross extrusion.

The material was also analyzed with light microscope and the density of collagen, fibroblast cellularity, extent of fibrosis, reparative phenomena, mitosis and nucleoli were observed at different times.

It was considered high cellularity of fibroblasts when more than 70 fibroblasts per high power field (x40 microscope Olympus BL50) were observed; moderate cellularity when there were 20 to 70 fibroblasts per field and little cellularity when less than 20 fibroblasts per field were observed.

The extent of fibrosis was considered large when it occupied more than 1 high power field; moderate extension when between 1 and half field, and small when smaller than 0.5 .
As to reparative phenomena, the mitoses in fibroblasts were considered high when their score was greater than three mitoses per three high-power fields, low when their score was below three, and absent when mitoses were not observed. The evaluation of the fibroblast nucleoli was quantified as: 1 - present in most of the cells, 2 - present in few cells and 3 - absent. The evaluation of the collagen arrangement was considered: L-loose, L / D - Intermediate and D - dense.

The clinical evolution of animals was performed by observing the general appearance, body weight, water intake, food intake and urine output, and biochemical analyses of blood glucose, urine glucose and plasma insulin dosage.

The variables which accepted normality, such as A and B measures and tensile strength, were statistically analyzed with the Shapiro Wilk Test.

\section{Results}

The animals of group G2 that received alloxan, showed clinical and laboratory parameters compatible with severe diabetes, characterized by fasting glucose greater than $300 \mathrm{mg} / \mathrm{dl}$, glycosuria equal or superior to $3+$ and low plasma insulin levels when compared to non-diabetic control group (G1). Elevated glucose and low insulin blood values remained throughout the study (Tables 1 and 2).

TABLE 1 - Measurements of fasting glucose in $\mathrm{mg} / \mathrm{dl}$ in the different moments of G1 and G2.

\begin{tabular}{ccc}
\hline $\begin{array}{c}\text { EVALUATION } \\
\text { MOMENTS }\end{array}$ & $\begin{array}{c}\text { G1 } \\
\text { (CONTROL) }\end{array}$ & $\begin{array}{c}\text { G2 } \\
\text { (DIABETIC) }\end{array}$ \\
\hline SURGERY (MO) & $126.86 \pm 22.5$ & $375.6 \pm 73.95$ \\
3M 4 DAYS (M1) & $84.83 \pm 24.86$ & $372.6 \pm 53.32$ \\
3M 14 DAYS (M2) & $111.92 \pm 13.92$ & $369.42 \pm 45.01$ \\
3M 21 DAYS (M3) & $104.42 \pm 23.56$ & $387.33 \pm 66.57$ \\
4 MONTHS (M4) & $107.18 \pm 13,97$ & \\
\hline
\end{tabular}

TABLE 2 - Measurements of serum insulin U/ml, at various moments in groups G1 and G2.

\begin{tabular}{ccc}
\hline $\begin{array}{c}\text { EVALUATION } \\
\text { MOMENTS }\end{array}$ & $\begin{array}{c}\text { G1 } \\
\text { (CONTROL) }\end{array}$ & $\begin{array}{c}\text { G2 } \\
\text { (DIABETIC) }\end{array}$ \\
\hline SURGERY (MO) & $14.91 \pm 7.07$ & $2.28 \pm 0.74$ \\
3M 4 DAYS (M1) & $7.57 \pm 11.54$ & $3.14 \pm 1.28$ \\
3M 14 DAYS (M2) & $8.07 \pm 8.2$ & $2.11 \pm 2.61$ \\
3M 21 DAYS (M3) & $7.98 \pm 5.1$ & $3.32 \pm 1.89$ \\
4 MONTHS (M4) & $10.15 \pm 3.85$ & $2.67 \pm 1.92$ \\
\hline
\end{tabular}


TABLE 3 - Average values of tensile strength in several moments in groups G1 and G2.

\begin{tabular}{cccccc}
\hline $\begin{array}{c}\text { EVALUATUION } \\
\text { MOMENTS }\end{array}$ & N & $\begin{array}{c}\text { G1 } \\
\text { (CONTROL) }\end{array}$ & N & $\begin{array}{c}\text { G2 } \\
\text { (DIABETIC) }\end{array}$ & $\mathbf{p}$ \\
\hline M1 & 10 & 723.3 & 9 & 893.5 & 0.2941 \\
M2 & 9 & 1985 & 10 & 776.4 & 0.0280 \\
M3 & 10 & 997.2 & 10 & 821.8 & 0.2951 \\
M4 & 10 & 1527 & 10 & 759.9 & 0.0059 \\
\hline
\end{tabular}

Diabetic animals showed a progressive decline in general condition, body weight loss and weight gain significantly lower than that observed in control animals after induction of diabetes. Table 3 shows the mean and standard deviation of tensile strength in groups 1 and 2, in the different studied moments. Figure 1 illustrates these values and shows that the tensile strength of scars in diabetic rats was lower than that observed in control animals, with statistically significant differences in moments 2 and 4 .

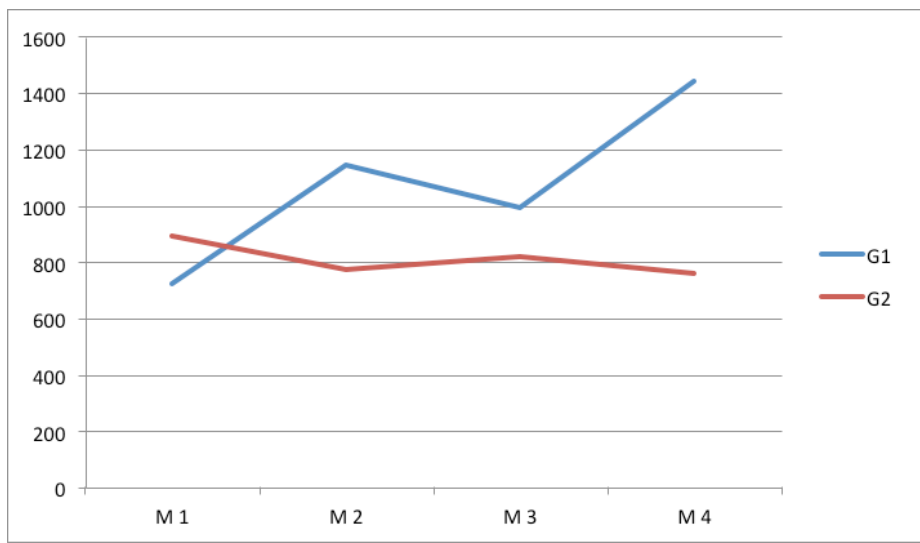

FIGURE 1 - Average tensile strength ( $\mathrm{g}$ ) in group 1 (control) and group 2 (diabetic). At the moments 2 and 4 there was significant difference compared with the moments 1 and 3 .

Table 4 shows the mean and standard deviation of the muscular wall thickness, adjacent to the surgical wound, in groups 1 and 2 in the different studied moments.

TABLE 4 - Mean and standard deviation related to the thickness of the muscle wall adjacent to the surgical scar.

\begin{tabular}{lccccc}
\hline $\begin{array}{l}\text { EVALUATION } \\
\text { MOMENTS }\end{array}$ & N & $\begin{array}{c}\text { G1 } \\
\text { (CONTROL) }\end{array}$ & N & $\begin{array}{c}\text { G2 } \\
\text { (DIABETIC) }\end{array}$ & p \\
\hline M1 & 10 & $0.30(0.04)$ & 10 & $0.20(0.09)$ & 0.0174 \\
M2 & 10 & $0.37(0.11)$ & 10 & $0.20(0.05)$ & 0.0010 \\
M3 & 10 & $0.41(0.07)$ & 10 & $0.24(0.08)$ & 0.0007 \\
M4 & 10 & $0.46(0.08)$ & 10 & $0.13(0.04)$ & 0.0001 \\
\hline
\end{tabular}

Group 1 showed increased thickness of the muscular wall at all times. Figure 2 shows these values.

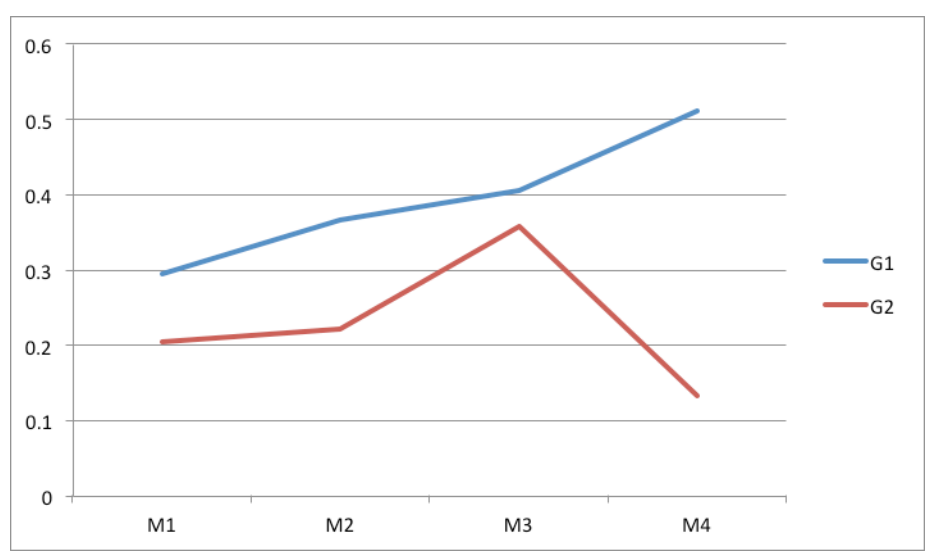

FIGURE 2 - Average thickness of the bundle of collagen from muscular wall adjacent to the surgical scar (A). In group 1 the averages were higher at all times.

Table 5 shows the values of the collagen beam width in the center of the surgical scar. It was observed that group 1 showed higher values than those observed in group 2 throughout the experiment, with a statistically significant difference in moments 2 and 4 . Figure 3 shows these values.

TABLE 5 - Mean and standard deviation related to collagen bundle thickness in the center of the surgical scar

\begin{tabular}{lccccc}
\hline $\begin{array}{l}\text { EVALUATION } \\
\text { MOMENTS }\end{array}$ & N & $\begin{array}{c}\text { G1 } \\
\text { (CONTROL) }\end{array}$ & N & $\begin{array}{c}\text { G2 } \\
\text { (DIABETIC) }\end{array}$ & p \\
\hline M1 & 10 & $0.26(0.13)$ & 10 & $0.22(0.11)$ & 0.4941 \\
M2 & 10 & $0.42(0.11)$ & 10 & $0.23(0.07)$ & 0.0013 \\
M3 & 10 & $0.32(0.11)$ & 10 & $0.23(0.07)$ & 0.0938 \\
M4 & 10 & $0.30(0.13)$ & 10 & $0.10(0.02)$ & 0.0006 \\
\hline
\end{tabular}

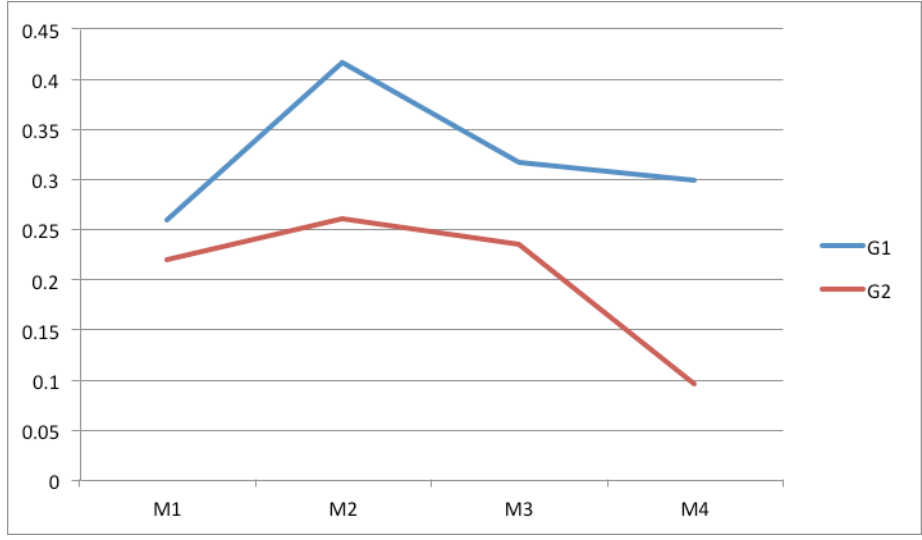

FIGURE 3 - Average related to the collagen bundle thickness in the center of the scar (B). At the moments 2 and 4 , group 1 means were higher than those in group 2. 
Light microscopy showed that collagen density in group 1 was the loose type in the first two weeks. In the underlying weeks, collagen started to become denser and contracted. The results were similar in the diabetic group, however, there was a longer delay for the collagen to contract and become denser.

As to fibroblast cellularity and extent of fibrosis observed in the scar, it was found that the former was very variable in the first two weeks of healing in G1, tending to medium and low values in the last two weeks. The extent of fibrosis in this group was homogeneous in the first two weeks, declining over the last two moments.

In contrast, it was observed that the wounds in group G2 maintained a high cellularity of fibroblasts, even at late stages of healing. It was also noted an irregular distribution of fibrosis.

Regarding reparative phenomena, it was observed that non diabetic control animals showed high concentration of mitoses in the first week of healing, which decreased in the second week and disappeared in the last two moments. In G2, it was observed decrease in the number of mitoses in the moments M1 and M2 concerning the control group, and the frequency of mitosis was similar in both groups at other moments. Similar behavior occurred with the nucleoli.

\section{Discussion}

Diabetes mellitus (DM) is a systemic disease known to produce metabolic changes, characterized by hyperglycemia, hypertriglyceridemia and insulin resistance. However, diabetes can also impair the healing of surgical wounds by causing delay in the migration of leukocytes and macrophages interfere with the metabolism of collagen and produce changes in the biomechanics of scars ${ }^{6,7}$.

The alloxan diabetes is a classic animal model used by researchers around the world. It was first described by Lukens in 1942 and produces all clinical and laboratory changes observed in human diabetes.

Although there are reports in the literature on the deleterious effects of alloxan in wound healing, several experimental studies have shown that quantitative and qualitative changes of collagen fibers are due to diabetes and not exactly due to alloxan ${ }^{8,9}$.

Furthermore, the surgery was performed three months after the induction of diabetes by alloxan, a period in which the side effects of this drug were no longer present.

The restoration of the strength of a tissue is an important aspect of wound healing. This process requires the deposition of appropriate amounts of extracellular matrix components, particularly collagen fibers in the wound area.
Thus, the use of a tensile strength to analyze the healing process has been widely used.

In a recent study conducted in our laboratory, we observed a significant reduction in the mechanical strength of ileum and colon rat anastomosis using an experimental model of chronic diabetes, with similar characteristics to the one used in this study ${ }^{7,8}$.

It was observed that the tensile strength in the wall, at the beginning of the study, $4^{\text {th }}$ postoperative day, was similar in both groups. However, as the healing reparatory phenomena had just begun, it is likely that the tensile strength could only be due to the presence of the suture in the wall. In subsequent moments, it was possible to realize that on days 7 and 30 there was a sharp decrease in tensile strength in the diabetic group. On the 14th day after surgery, although no significant difference was observed between the two groups, there was a tendency to lower values of tensile strength in the treated group.

Therefore the tensile strength is not a suitable method for the study of healing in sutures or anastomosis during the first days ${ }^{9,10}$. In the subsequent moments, when the tensile strength values tended to decrease in the diabetic animals, it was possible to assume that the treated animals had a decrease in collagen synthesis or imbalance in the synthesis and lysis.

It is known that diabetes is one of the most important factors in the healing of surgical wounds, once it can impair metabolic and biomechanical properties of collagen in sutures and anastomosis.

Most of the studies of tensile strength in diabetic animals have been performed in intestinal anastomosis and skin but not in the abdominal wall.

The abdominal wall has been further studied to analyze the healing of sutures or synthetic materials such as surgical meshes ${ }^{7,11,12}$. Therefore, the histological and morphometric analysis performed in this study provides more support to understand the mechanisms by which diabetes alters the healing of the abdominal wall.

Through light microscopy, we observed a greater difficulty for the collagen to contract and become denser in treated animals, as well as a high cellularity of fibroblasts in later moments. Diabetic animals also showed a decrease in the number of mitoses and nucleoli when compared to the control group, indicating a lower collagen synthesis.

Morphometry has been another method used to study the effects of experimental diabetes on the healing of bones, skin, mesentery and intestinal anastomosis ${ }^{13-15}$.

In this experiment, Masson trichrome staining was used, although picrocirius is known to be more specific. Noteworthy is the fact that none of these methods allow to differentiate types of collagen, only its density. 
The average thickness of collagen bundle in the wall adjacent to the surgical scar and in the surgical scar center was utilized. In both cases it was observed that there was a greater width of collagen beam in the operated abdominal wall of control animals, except in moments 1 and 3 regarding the thickness of the beam in the center of the scar which, despite not statistically, showed a trend of greater collagen density in non-diabetic animals.

This way, there seems to be a direct relationship between the lower collagen density and the lower breaking strength of abdominal wall segments studied in diabetic animals.

These findings are different from our previous studies in which the morphometry in the ileum and colon anastomosis of rats showed that collagen fibers occupied more space in the anastomosis of diabetic animals. However, in these animals a change in the arrangement and distribution of these collagen fibers was observed, as examined by optical microscopy and scanning electron microscopy. It was concluded that quantitative changes in collagen could not be the cause of decreased tensile strength ${ }^{13}$.

According to our study, it is likely that both structural changes in the collagen and its lower concentration measured by morphometric analysis could explain changes in the breaking strength measurement.

It is well established that surgical patients with DM have impaired wound healing with increased incidence of infection, which prolongs hospitalization and even increases the mortality rate.

We believe it is of great importance to study the mechanisms by which the disease interferes with the healing of both the abdominal wall and the viscera, so that it is possible propose therapeutic measures aimed at minimizing the harmful effects of the disease and its consequences.

One form of treatment to enhance the healing of incisional wound has been suggested in diabetic rats: lowenergy extracorporeal shock wave treatment (ESWT) has been reported as a method for accelerating the healing of chronic wounds, promoting revascularization and tissue regeneration. It is not known whether such treatment could also improve healing of acute incisional wounds in diabetic animals. In this study, it was observed that animals that had received ESWT showed an improvement in the tensile strength of the wound and in hydroxyproline levels in tissue, as well as an increase in the numbers of fibroblasts and collagen fibers ${ }^{16}$.

Therefore, it is essential that studies be conducted in an attempt to minimize the significant structural changes of collagen that occur in the abdominal wall in experimental animals, which certainly also occur in humans.

\section{Conclusions}

1 - Alloxanic diabetes is a good model for the study of disease complications in experimental animals;

2 - The tensile strength of the abdominal wall changes in treated animals;

3 - The morphometric study shows important changes in the bundle of collagen in the adjacent wall and in the center of the surgical scar in treated animals;

4 - Histological examination by light microscopy shows a greater difficulty for the collagen to contract and become denser in the treated animals.

\section{References}

1. American Diabetes Association - Diabetes Statistics. Data from the 2011 National Diabetes Fact Sheet. Available from: http://www. diabetes.org/diabetes-basics/diabetes-statistics/

2. Wild S, Roglic G, Green A, Sicree R, King H. Global prevalence of diabetes. Estimator for the year 2000 and projections for 2030 . Diabetes Care. 2004;27(5):1047-53

3. Sociedade Brasileira de Diabetes. Estimativa do número de pacientes com diabetes no Brasil, 2007. Disponível em: http://www.diabetes. org.br/calculadora/número-de-diabeticos

4. Sociedade Brasileira de Diabetes. (SBD). Consenso Brasileiro de Diabetes, 2002. Disponível em: http://www.diabetes.org.br/ educacao/docs/Consenso_atual_2002.pdf

5. Rosenberg, CS. Wound healing in the patient with Diabetes Mellitus. Nurs Clin North Am. 1990;25(1):247-61.

6. Ekmektzoglou KA, Zografos, GC. A concomitant review of the effects of diabetes mellitus and hypothyroidism in wound healing. World J Gastroenterol. 2006;12(17):2721-9.

7. Minossi JG, Caramoni CA, Leite CVS, Naresse LE. Comparative study between two techniques of incisional hernia polypropilene mesh repair in rabbits. Acta Cir Bras. 2010;25(5):423-7.

8. Machado JLM, Ortolani EVP, Spadella CT. Anastomotic healing in ileum and colon alloxan-induced diabetic rats. Acta Cir Bras. 2009;24:57-61.

9. Minossi JG, Leite CVS, Naresse LE, Rodrigues MAM, Burini RC, Kobayasi S. Ação do diclofenaco de sódio em anastomoses realizados no cólon distal de ratos. Acta Cir Bras. 1996;11(2):116-20.

10. Minossi JG, Leite CVS, Naresse LE, Rodrigues MAM, Curi PR, Kobayasi S. Ação do diclofenaco de sódio em anastomoses realizados no intestino delgado de ratos. Acta Cir Bras. 1998;13(1):37-43.

11. Ross LF, Rames RR, Kestering DM, Sold MS, Ely JB, d'Acampora AJ. Tensile strength study of the abdominal wall following laparotomy synthesis using three types of surgical wires in Wistar rats. Acta Cir Bras. 2008;23:73-7.

12. Gianlup A, Trindade MRM. Comparação entre o uso do fio inabsorvível (polipropileno) e fio absorvível (poliglactina 910) na fixação de prótese de polipropileno em correção de defeitos músculo-aponeuróticos da parede abdominal. Estudo experimental em ratos. Acta Cir Bras. 2004;19:94-102.

13. Ortolani EVP, Spadella CT, Caramori C, Machado JLM, Gregório EA, Rabello K. Microscopic, morphometric and ultrastructural analysis of anastomotic healing in the intestine of normal and diabetic rats. Exp Clin Endocrinol Diabetes. 2008;116(4):198-202.

14. Ortolani EVP, Spadella CT, Machado JLM, Kobayasi S. The 
evaluation of healing parameters in the colon of diabetic rats without surgical injury. Acta Cir Bras. 2004;19(3):286-95

15. Alkan A, Erdem E, Gunhan O, Karasu C. Histomorphometric evaluation of the effect of doxycyline on the healing of bone defects in experimental diabetes mellitus: a pilot study. J Oral Maxillofac Surg. 2002;60:898-904.

16. Yang G, Luo C, Yan X, Cheng L, Chai Y. Extracorporeal shock wave treatment improves incisional wound healing in diabetic rats. Tohoku J Exp Med. 2011;225(4):285-92.

\section{Correspondence:}

José Guilherme Minossi

Faculdade de Medicina de Botucatu, Departamento de Cirurgia e Ortopedia

Campus da UNESP

Distrito de Rubião Jr., s/n ${ }^{\circ}$ Anexo Verde

18618-970 Botucatu - SP Brasil

Tel.: (55 14)3880-1428

jminossi@uol.com.br

Received: Oct 17, 2013

Review: Dec 18, 2013

Accepted: Jan 20, 2014

Conflict of interest: none

Financial source: none

${ }^{1}$ Research performed at Experimental Surgery Laboratory, Faculty of Medicine, Sao Paulo State University (UNESP), Botucatu-SP, Brazil. 